\title{
SUSTAINED AND PROMOTER DEPENDENT BONE MORPHOGENETIC PROTEIN EXPRESSION BY RAT MESENCHYMAL STEM CELLS AFTER BMP-2 TRANSGENE ELECTROTRANSFER
}

\author{
Elisabeth Ferreira ${ }^{1,2}$, Esther Potier ${ }^{1,3}$, Pascal Vaudin ${ }^{4,5}$, Karim Oudina $^{1}$, Morad Bensidhoum ${ }^{1}$, Delphine Logeart-
} Avramoglou$^{1}$, Lluis M Mir ${ }^{6,7}$ and Hervé Petite ${ }^{1 *}$

${ }^{1}$ Laboratoire Biomecanique et Biomateriaux Ostéo-Articulaires (B2OA), CNRS UMR 7052, Paris, France

${ }^{2}$ Center for Advanced Orthopaedic Studies, Beth Israel Deaconess Medical Center,

Harvard Medical School, Boston, MA, USA

${ }^{3}$ Eindhoven University of Technology, Biomedical Engineering, Orthopaedic Biomechanics, Eindhoven, The Netherlands

${ }^{4}$ Microenvironnement de l'Hématopoïèse et Cellules Souches, INSERM, EA3855, Tours, France

${ }^{5}$ Physiologie de la Reproduction et des Comportements, UMR 6175, Université François Rabelais, Tours, France

${ }^{6}$ CNRS UMR 8203 Institut Gustave Roussy, Villejuif, France

${ }^{7}$ Université Paris-Sud, UMR 8203, Paris, France

\begin{abstract}
Transplantation of mesenchymal stem cells (MSCs) with electrotransferred bone morphogenetic protein-2 (BMP2) transgene is an attractive therapeutic modality for the treatment of large bone defects: it provides both stem cells with the ability to form bone and an effective bone inducer while avoiding viral gene transfer. The objective of the present study was to determine the influence of the promoter driving the human BMP-2 gene on the level and duration of BMP-2 expression after transgene electrotransfer into rat MSCs. Cytomegalovirus, elongation factor- $1 \alpha$, glyceraldehyde 3-phosphate dehydrogenase, and beta-actin promoters resulted in a BMP-2 secretion rate increase of 11-, 78-, 66- and 36-fold over respective controls, respectively. In contrast, the osteocalcin promoter had predictable weak activity in undifferentiated MSCs but induced the strongest BMP-2 secretion rates in osteoblastically-differentiated MSCs. Regardless of the promoter driving the transgene, a plateau of maximal BMP-2 secretion persisted for at least $21 \mathrm{~d}$ after the hBMP-2 gene electrotransfer. The present study demonstrates the feasibility of gene electrotransfer for efficient BMP-2 transgene delivery into MSCs and for a three-week sustained BMP-2 expression. It also provides the first in vitro evidence for a safe alternative to viral methods that permit efficient BMP-2 gene delivery and expression in MSCs but raise safety concerns that are critical when considering clinical applications.
\end{abstract}

Keywords: Bone morphogenetic proteins; mesenchymal stem cells; gene delivery; electroporation; promoter activity; marrow stromal cells.

*Address for correspondence:

Hervé Petite, Ph.D.

Laboratoire Biomecanique et Biomateriaux OstéoArticulaires (B2OA)

CNRS UMR 7052

Université Paris Diderot Paris 7

10 Avenue de Verdun

75010 Paris, France

Tel : + 33157278538

Fax : + 33157278571

E-mail: herve.petite@univ-paris-diderot.fr
Introduction

Local and sustained delivery of osteoinductive growth factors, i.e., the bone morphogenetic proteins (BMPs) which have the remarkable capability of inducing the biological cascade leading to new bone formation (Urist et al., 1979; Wozney et al., 1988), has been used as alternatives to autologous bone grafts to promote bone regeneration. One such approach consists of delivering BMPs locally using genetically modified cells that overexpress a BMP transgene (Baltzer et al., 2000; Lieberman et al., 1998; Musgrave et al., 2000). Mesenchymal stem cell (MSC)-mediated BMP delivery is currently a promising but not yet fully explored gene therapy approach for bone tissue repair (Blum et al., 2003; Hsu et al., 2007; Tsuchida et al., 2003) since MSCs are both "mini-factories" for BMP secretion and a source of osteoprogenitor cells.

Because of its ease of application and efficiency, the DNA electrotransfer method has become a routine technique for introducing foreign genes into mammalian cells (Daud et al., 2008; Duces et al., 2008; Neumann et al., 1982; Wu et al., 2001). This method is particularly attractive in the context of MSC-mediated BMP delivery because it (i) leads to transient expression of the transgene, a situation that fits the bone repair process which requires expression of BMPs only until the bone is healed (i.e, a few weeks); and (ii) limits the risk of DNA integration, which is of paramount importance for patient safety in the case of bone repair, a non-lethal clinical condition.

Regardless of the method used to transfer a BMP transgene into MSCs (McMahon et al., 2006; OlmstedDavis et al., 2002), the transgene expression efficiency depends not only on the transfer efficiency of the delivery system, but also on the level and duration of transgene expression, which is dependent on the promoter used to drive the transcription of the transgene. Cellular promoters such as those for the genes encoding $\beta$-actin and elongation factor-1 $\alpha(\mathrm{EF}-1 \alpha)$ were reported to drive higher levels of transgene expression as well as prolonged transgene expression compared to viral promoters (Gill et al., 2001; Hong et al., 2007; Sakurai et al., 2005; Sugiyama et al., 1988). Notably, the EF-1 $\alpha$ promoter induced higher levels of transgene expression than the viral CMV promoter in 
mesenchymal progenitor cells (Byun et al., 2005). The efficiency of cellular promoters has been shown to be cell specific and dependent on cell activity (Doll et al., 1996; Durieux et al., 2005; Ramezani et al., 2000; Spenger et al., 2004). While studies indicated that osteoblastic specific promoters, including the promoter of the osteocalcin gene, led to increase in transgene expression over time for BMP2 expression in MSCs (Kumar et al., 2005), the effect of various cellular and tissue-specific promoters on the level and duration of BMP-2 expression in MSCs has not yet been well investigated.

For these reasons, the present study determined the influence of the promoter driving the hBMP-2 transgene on level and duration of gene expression after transgene electrotransfer into rat MSCs. The activity of the viral cytomegalovirus (CMV) promoter (the standard promoter used in most BMP transgene expression systems (Chuang et al., 2007; Lieberman et al., 1998; Lou et al., 1999; Musgrave et al., 2000)) was compared to the activity of mammalian cell promoters including those for the $\beta$-actin, EF-1 $\alpha$, eukaryotic initiation factor 4A1 (eIF-4A1), glyceraldehyde 3-phosphate dehydrogenase (GAPDH) and the tissue-specific fibronectin and OG-2 (osteocalcin) promoters.

To this aim, plasmids encoding either the lacZ reporter gene (which directs the synthesis of the beta-galactosidase enzyme) or the human BMP-2 cDNA, both fused to one of the tested promoters, were electrotransferred into rat MSCs under previously optimised gene electrotransfer parameters (Ferreira et al., 2008) (under optimal conditions for efficient gene electrotransfer into MSC, viability of MSCs was about $70 \%$ and transfection rate was up to $30 \%$ ). Expression of beta-galactosidase and BMP-2 provided evidence that: (i) the CMV promoter was not the most efficient one in rat MSCs, and (ii) selection of the appropriate promoter could lead to modulation of BMP-2 expression as a function of the stage of MSC differentiation into an osteoblastic lineage. Most importantly, and to the authors' best knowledge, the present study is the first to demonstrate a three-week-sustained release of BMP-2 by electrotransferred MSCs.

\section{Materials and Methods}

\section{Cell source}

MSCs, obtained from the bone marrow of 4-week-old male Lewis rats, were isolated and expanded as previously described (Friedenstein et al., 1970; Pittenger et al., 1999). These cells were routinely cultured in alpha-minimum essential medium ( $\alpha$ MEM, Sigma-Aldrich, Lyon, France) supplemented with $10 \%$ foetal calf serum (PAA Laboratories, Pasching, Austria). MSCs from the fourth passage were used for the experiments.

\section{LacZ plasmid}

A panel of pDRIVE plasmids (InvivoGen, Toulouse, France), encoding the lacZ reporter gene under the control of one of either the CMV, eIF4A1, EF1- $\alpha$, $\beta$-actin, GAPDH, fibronectin or osteocalcin promoters, were prepared for electrotransfer into rat MSCs. The DNA was routinely amplified in DH5 $\alpha$ Escherichia coli bacteria (Life Technologies, Cergy Pontoise, France) and purified using commercially available kits according to the manufacturer's instructions (Plasmid Midi Kit, Qiagen, Courtaboeuf, France). DNA was resuspended in molecularbiology-grade water (Eppendorf, Le Pecq, France) at a concentration of $2 \mu \mathrm{g} / \mu \mathrm{L}$.

\section{Construction of plasmids encoding the hBMP-2 cDNA}

All constructs were generated in the pcDNA3.1(+) plasmid (Life Technologies). hBMP-2 cDNA was first amplified from the pcDEF3/hBMP-2 plasmid (a kind gift from Dr. Katagiri, Department of Biochemistry, Showa University, Tokyo, Japan) by polymerase chain reaction (PCR) using primers designed with EcoRI and XbaI restriction sites. All primers were purchased from Sigma-Aldrich, and their sequences are shown in Table 1. The hBMP-2 fragment was then sub-cloned into the EcoRI/XbaI restriction site in the multiple cloning site of pcDNA3.1(+), downstream of the human cytomegalovirus immediate-early promoter included in the vector. Subsequently, the CMV promoter sequence was excised from the pcDNA3.1(+)/hBMP-2

Table 1. Sequences of the primers used for the construction of the plasmids encoding the hBMP-2 transgene under the control of the tested promoters. The underlined portions of the primer sequences indicate introduced restriction sites. (F) stands for forward. (R) stands for reverse.

\begin{tabular}{|c|c|}
\hline Primer name & 5'-3' sequence \\
\hline (F) EcoRI-hBMP-2 & TTGAATTCGCCGCCATGAATTCATGGTGGCCGGGACCCGCTG \\
\hline (R) $X b a I$-hBMP-2 & TTTCTAGAT TCTAGACTAGCGACACCCACAACCTT \\
\hline (F) HindIII- $\beta$-actin & GGAAGCTTGTTCCATGTCCTTATATGGACTCA \\
\hline (R) SpeI- $\beta$-actin & GGACTAGTGGTGAGCTGCGAGAATAGCC \\
\hline (F) KpnI-EF-1 $\alpha$ & GGGGTACCGGAGCCGAGAGTAATTCATACAAA \\
\hline (R) BamHI-EF-1 $\alpha$ & GGGATCCGTTGCTTTGAATTAGCGGTGG \\
\hline (F) HindIII-eIF-4A1 & GGAAGCTTTCGCTACAATATTTTCCTGAACG \\
\hline (R) SpeI-eIF-4A1 & GGACTAGTGGTC CTTAGAATCTAGGGCGG \\
\hline (F) HindIII-fibonectin & GGAAGCTTTAACAGCTGCAAGGTCGTG \\
\hline (R) SpeI-fibronectin & GGACTAGTGTGAGACGGTGGGGGAGA \\
\hline (F) HindIII-GAPDH & GGAAGCTTAGTT CCCCAACTTTCCCG \\
\hline (R) SpeI-GAPDH & GGACTAGTGTGTCTCAGCGATGTGGCTC \\
\hline (F) HindIII-OG-2 & GGAAGCTTCTAGTCACTCCCAGAGCCT \\
\hline (R) SpeI-OG-2 & GGACTAGTGTGTCTGCTAGGTGTGCACC \\
\hline
\end{tabular}


vector by digestion with MluI and NheI and the vector was purified, blunt-ended, and self-ligated to generate the pcDNA3.1/CMV/hBMP-2 construct. Fragments of the tested promoters (Table 2) were amplified by PCR from the respective pDRIVE plasmids using primers listed in Table 1 , purified and cloned upstream of the hBMP-2 sequence in the pcDNA3.1/CMV/hBMP-2 plasmid. The integrity of the constructs was confirmed by enzymatic restriction analysis. DNA was routinely amplified in DH5 $\alpha$ Escherichia coli bacteria (Life Technologies), purified using the Plasmid Midi Kit (Quiagen), and resuspended in molecular-biologygrade water at a concentration of $2 \mu \mathrm{g} / \mu \mathrm{L}$.

\section{LacZ transgene electrotransfer into MSCs}

LacZ electrotransfer into rat MSCs was performed using the Cliniporator ${ }^{\mathrm{TM}}$ device (IGEA, Carpi, Italy) and established techniques (Ferreira et al., 2008; Pucihar et al., 2002). Briefly, cells were trypsinised, centrifuged at $500 \mathrm{~g}$ for $10 \mathrm{~min}$, and then resuspended in Spinner's minimum essential medium electropulsation buffer (S-MEM, Life Technologies) at a concentration of $10^{7}$ cells $/ \mathrm{mL}$. A $50 \mu \mathrm{L}$ MSC suspension aliquot was electropulsed with $15 \times 10^{11}$ copies of each plasmid by applying a train of eight electric pulses $(100 \mu \mathrm{s})$ at $1500 \mathrm{~V} / \mathrm{cm}$ and at a $1 \mathrm{~Hz}$ frequency. After electroporation, the cells were collected, suspended in $50 \mu \mathrm{L}$ of electropulsation buffer (to prevent drying) and allowed to recover at $22{ }^{\circ} \mathrm{C}$ for $10 \mathrm{~min}$. Subsequently, culture medium was added and the cells were maintained under standard cell culture conditions $\left(37^{\circ} \mathrm{C}, 95 \% \mathrm{CO}_{2}\right.$, $5 \% \mathrm{O}_{2}$ ) for $48 \mathrm{~h}$. All experiments were repeated at two separate times.

\section{Quantification of beta-galactosidase production}

Forty-eight hours post transfection, adherent MSCs were trypsinised, centrifuged and resuspended in $150 \mu \mathrm{L}$ Reporter Lysis Buffer 1X (Promega, Charbonnièresles-bains, France). Quantification of $\beta$-galactosidase activity in the cell lysates was carried out as previously described (Ferreira et al., 2008). Briefly, $70 \mu \mathrm{L}$ of cell lysate was incubated with the $\beta$-galactosidase substrate, o-nitrophenyl- $\beta$-D galactopyranoside (Amsresco IncInterchim, Montluçon, France), at $37{ }^{\circ} \mathrm{C}$ for $30 \mathrm{~min}$. The enzymatic reaction was stopped by addition of $1 \mathrm{M}$ sodium carbonate, and light transmission was determined spectroscopically at $420 \mathrm{~nm}$ using the $\mu$ Quant system (BioTek Instruments Inc, Colmar, France). Beta-galactosidase activity in each sample tested was normalised to total DNA content.

\section{hBMP-2 transgene electrotransfer into MSCs}

hBMP-2 transgene electrotransfer into rat MSCs was essentially carried out as described in the section "lacZ transgene electrotransfer into MSCs". In this specific case, a $50 \mu \mathrm{L}$ aliquot of MSC suspension $\left(10^{7}\right.$ cells/ $\mathrm{mL}$ ) was electropulsed with $12 \times 10^{11}$ copies of hBMP-2 plasmid. Following incubation after electropulsation, culture medium was added and the cell suspension was seeded in 12-well plates at a density of 20,000 cells $/ \mathrm{cm}^{2}$. These cells were maintained under standard cell culture conditions $\left(37^{\circ} \mathrm{C}, 95 \% \mathrm{CO}_{2}, 5 \% \mathrm{O}_{2}\right)$ for $1,2,4,7,10$, 14 and $21 \mathrm{~d}$. Twenty-four hours after gene electrotransfer,
Table 2. Origin and length of the different promoters tested.

\begin{tabular}{|c|c|c|}
\hline Promoter name & Origin & Size (bp) \\
\hline CMV & viral & 587 \\
\hline EF-1 $\alpha$ & rat & 1314 \\
\hline$\beta$-actin & human & 1454 \\
\hline GAPDH & human & 483 \\
\hline eIF4AI & human & 523 \\
\hline fibronectin & human & 787 \\
\hline osteocalcin & mouse & 1012 \\
\hline
\end{tabular}

the MSC culture media was supplemented with $10 \mu \mathrm{g} / \mathrm{mL}$ heparin (Sigma). These experiments were repeated at two separate times.

\section{Kinetics of BMP-2 production by MSCs}

BMP-2 production by electrotransferred MSCs was quantified in cell supernatants at prescribed time points after transgene electrotransfer using an ELISA kit (Quantikine, R\&D Systems, Lille, France) according to the manufacturer's instructions. Briefly, at day 1, 2, 4, 7, 10, 14, 17 and 21 after transgene electrotransfer, supernatants were collected into silicon tubes. At each of the aforementioned time points, the respective adherent cells were trypsinised, counted and/or resuspended in lysis buffer for further biochemical analyses. Supernatant media samples were stored at $-80^{\circ} \mathrm{C}$ until ELISA analysis of BMP-2 content. The amount of protein secreted was expressed per $10^{6}$ cells per $24 \mathrm{~h}$.

\section{BMP-2 mRNA expression}

Human BMP-2 mRNA expression in MSCs was measured at days 4, 7, 10, 14 and 21 after transgene electrotransfer. Cytoplasmic RNA was extracted from cells using TRIzol reagent (Life Technologies) according to the manufacturer's protocol. RNA concentrations were quantified by measuring the optical density of each sample at $260 \mathrm{~nm}$. RNA $(1 \mu \mathrm{g})$ was transcribed onto cDNA using the ThermoScipt ${ }^{\mathrm{TM}}$ kit and oligo-dT primers $(50 \mu \mathrm{M})$ (Life Technologies), according to the manufacturer's instructions. Real time-PCR was performed on an iCycler thermal cycler (Bio-Rad Laboratories, Marnes-la-Coquette, France) using the SYBR Green Mix kit (Bio-Rad Laboratories). The reaction mix contained 1X SYBR Green, 20-fold diluted cDNA and $0.2 \mu \mathrm{M}$ of each primer. Specific primers used for human BMP-2 (accession number: NM001200) and rat 18S rRNA (as the endogenous reference gene, accession number: M11188) were as follows: forward hBMP-2: 5'-AACACTGTGCGCAGCTTCC-3', reverse hBMP-2: 5'-CTCCGGGTTGTTTTCCCAC-3' $(74$ b p), forward rat $18 \mathrm{~S}$ rRNA: 5'-ACTCAACACGGGAAACCTCA-3', reverse rat 18S rRNA: 5'-AATCGCTCCACCAACTAAGA-3' (114 bp). It should be noted that the designed BMP-2 primers specifically recognise the human but not rat BMP-2 sequence. After a 10 min denaturation step at $95^{\circ} \mathrm{C}$, cDNA was amplified by performing 40 cycles of two steps: (i) at $95{ }^{\circ} \mathrm{C}$ for $15 \mathrm{~s}$, and (ii) at $60^{\circ} \mathrm{C}$ for $60 \mathrm{~s}$. Melting curve analyses were performed at the end of each amplification step. The hBMP-2 mRNA expression levels were normalised to those of the internal standard $18 \mathrm{~S}$ 
rRNA and reported as relative values $(\Delta \Delta \mathrm{CT})$ to those obtained from the control cell cultures. All experiments were performed in triplicate.

\section{Evaluation of MSC osteoblastic differentiation}

Alkaline phosphatase (ALP) activity of MSCs was determined at day 1, 2, 4, 7, 10, 14 and 21 after transgene electrotransfer using a commercial kit (Sigma Aldrich). Cells were washed with phosphate-buffered saline, and collected in $230 \mu \mathrm{L}$ lysis buffer. Briefly, $15 \mu \mathrm{L}$ of each cell lysate was incubated with the ALP substrate, p-nitrophenyl phosphate at $37^{\circ} \mathrm{C}$ for $10 \mathrm{~min}$ and the light transmission was read at $405 \mathrm{~nm}$. ALP activity was normalised to cellular DNA content. The DNA content in cell lysates was quantified using the Cyquant ${ }^{\circledR}$ Cell Proliferation Assay Kit (Life Technologies) according to the manufacturer's instructions.

\section{Determination of the plasmid copy number}

The plasmid copy number in rat MSCs was determined at days 2, 4, and 14 after hBMP-2 transgene electrotransfer using quantitative Real Time-PCR analysis. Briefly, a $50 \mu \mathrm{L}$ aliquot of MSC suspension $\left(1 \times 10^{7}\right.$ cells $\left./ \mathrm{mL}\right)$ was electropulsed with $12 \times 10^{11}$ copies of hBMP-2 plasmid. Cells electropulsed without DNA were used as controls. Following the post-electropulsation incubation time, culture medium was added and the cell suspension was seeded in $25 \mathrm{~cm}^{2}$ culture flasks. The cells were then maintained under standard $\left(37^{\circ} \mathrm{C}, 95 \% \mathrm{CO}_{2}, 5 \% \mathrm{O}_{2}\right)$ cell culture conditions for 2,4 , and $14 \mathrm{~d}$. At each time point, genomic DNA was extracted from the cells using standard protocols (Bensidhoum et al., 2004). Quantitative RT-PCR was performed as described in the section "BMP-2 mRNA expression" with reaction mixtures containing $1 \mathrm{X}$ SYBR Green, 70 ng DNA and $0.2 \mu \mathrm{M}$ of each hBMP-2 primers. Standards made of hBMP-2 cDNA (diluted in genomic DNA isolated from untreated rat MSCs) were prepared such that the plasmid copy number ranged from 1000 to $2 \times 10^{6}$ in $70 \mathrm{ng}$ genomic DNA (i.e., 200 to 0.1 plasmid copies per cell). A standard curve displaying a linear relationship between $\mathrm{Ct}$ values and the logarithm of the input plasmid copy number was generated. The number of plasmid copy in electrotransferred cells was calculated by extrapolation from the experimentally determined standard curve. These experiments were repeated on two separate occasions.

\section{Statistical analyses}

Statistical analyses of numerical data were performed using one-way ANOVA and the LSD test (for pairwise comparisons), and the Statgraphic centurion version $\mathrm{XV}$ software was used for these analyses. A $p$ value of less than 0.05 was considered significant.

\section{Results}

\section{Effect of the promoter driving transcription of a transgene on protein expression after transgene transfer into MSCs}

A series of plasmids encoding the lacZ reporter gene and the hBMP-2 cDNA under the control of the $\beta$-actin,
EF-1 $\alpha$, eIF-4A1, fibronectin, GAPDH, osteocalcin or CMV promoter were prepared. First, the influence of the promoter driving the lacZ reporter gene on the $\beta$-galactosidase expression in rat MSCs was determined $48 \mathrm{~h}$ after the electrotransfer of an equal number of copies of plasmid DNA. Beta-galactosidase production was clearly dependent on the promoter driving lacZ gene expression (Fig. 1a). The CMV, $\beta$-actin, EF- $1 \alpha$, eIF-4A1 and GAPDH promoters led to increased $\beta$-galactosidase production rate of 26-, 38-, 41-, 42- and 48-fold over pertinent controls, respectively. This result suggests that the CMV promoter was less efficient than either the $\operatorname{GAPDH}(p<0.05)$, eIF-4A1, EF- $1 \alpha$ and $\beta$-actin promoters in undifferentiated rat MSCs. The osteocalcin promoter had a weak activity (i.e., the $\beta$-galactosidase production rate was increased 2-fold over the control); this result was predictable as the osteocalcin gene is expressed at later stages of MSC osteoblastic differentiation. In addition, cell proliferation was not affected for all promoters tested: the lacZ-electrotransferred MSCs proliferated at rates similar to the control electropulsed cells (data not shown).

Second, the influence of the promoter driving the hBMP-2 transgene on BMP-2 expression was investigated by quantifying BMP-2 production using an ELISA assay, $48 \mathrm{~h}$ after electrotransfer into MSCs of an equal number of copies of plasmids encoding the hBMP-2 cDNA under the control of the tested promoters. LacZ electrotransferred MSCs were used as controls. BMP-2 secretion depended on the promoter driving hBMP-2 expression (Fig. 1b). The CMV, $\beta$-actin, EF-1 $\alpha$, eIF-4A1 and GAPDH promoters led to $0.4( \pm 0.1), 1.4( \pm 0.3), 3.0( \pm 1.6), 0.8( \pm 0.4)$ and $2.6( \pm 0.3) \mathrm{ng}$ BMP-2/48 h/10 6 cells, respectively. The CMV promoter was not the most efficient one in undifferentiated rat MSCs. The EF- $1 \alpha(p<0.05), \mathrm{GAPDH}$ $(p<0.05), \beta$-actin and eIF-4A1 promoters led to the greatest BMP-2 secretion rates (78-, 66-, 36- and 20-fold increase over pertinent controls, respectively).

\section{Effect of the promoter driving transcription of the BMP-2 transgene on long-term BMP-2 expression after transgene transfer into MSCs}

The kinetics of BMP-2 secretion as a function of the promoter driving the hBMP-2 transgene was next investigated during a 21-day time course study. The results presented in Fig. 2 provided the following evidence. First, a trend towards decreased BMP-2 secretion between day 2 and day 4 after hBMP-2 transgene electrotransfer into MSCs was observed for all, but the $\beta$-actin, promoters tested. The decrease in BMP-2 secretion was not correlated with the concomitant decrease in cell proliferation (data not shown). Second, regardless of the promoter driving the hBMP-2 transgene, an increase in BMP-2 secretion was observed from day 4 to day 14. Maximal amounts of BMP-2 were secreted at day 14 after gene electrotransfer. For example, MSCs electrotransferred with the hBMP-2 transgene under the control of the GAPDH and fibronectin promoters produced $4.8( \pm 0.3)$ and $1.5( \pm 0.2)$ ng BMP$2 / 24 \mathrm{~h} / 10^{6}$ cells, respectively. Additionally, regardless of the promoter driving the transgene, a plateau of maximal BMP-2 secretion persisted at least until day 21 after hBMP2 gene electrotransfer. It should be noted that, given the 

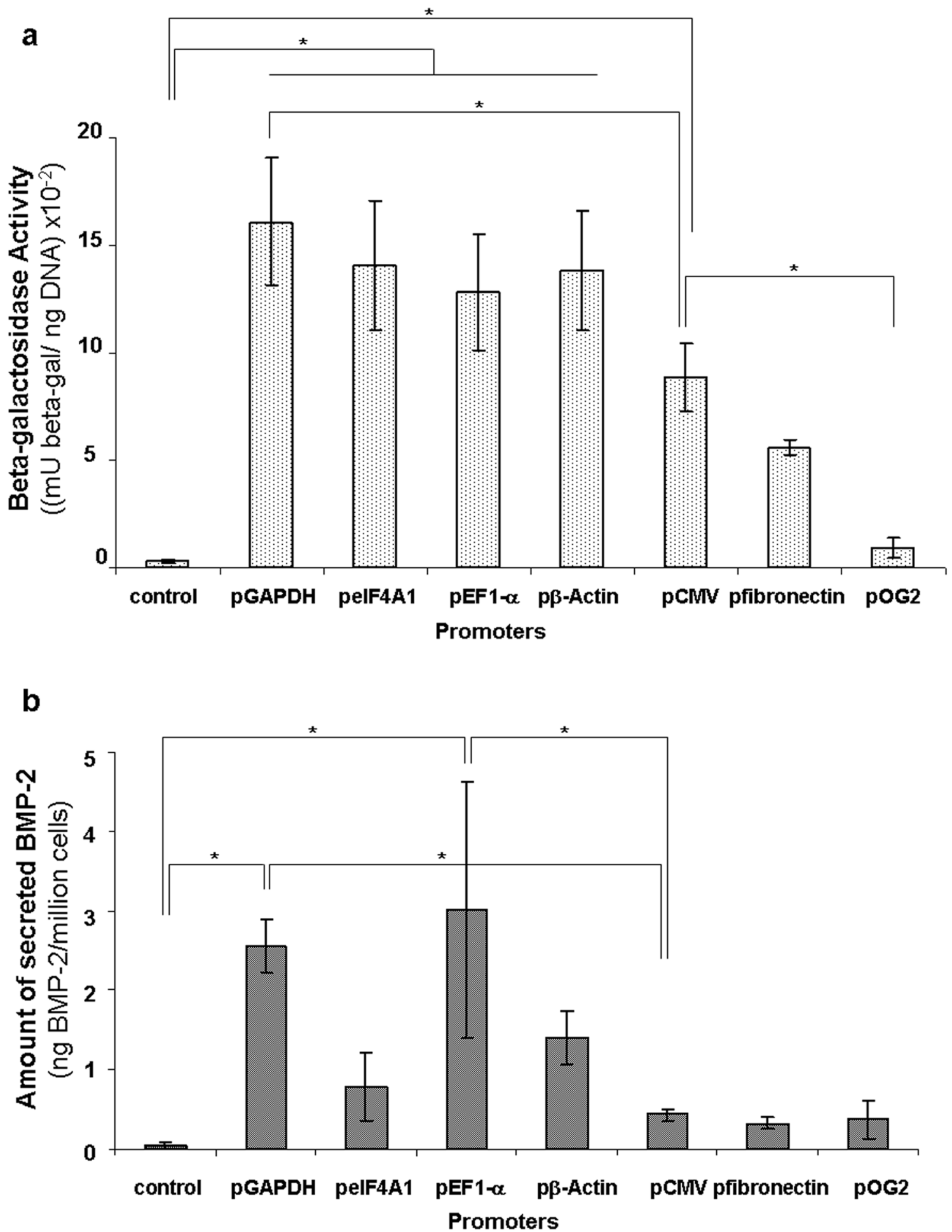

Fig.1. (A) Beta-galactosidase activity $48 \mathrm{~h}$ after electrotransfer into rat mesenchymal stem cells (MSCs) of an equal number of copies of plasmid encoding the lacZ gene driven by the tested promoters. Cells electropulsed without DNA were used as controls ( ${ }^{*} p<0.05$ ). (B) BMP-2 secretion $48 \mathrm{~h}$ after electrotransfer into MSCs of an equal number of copies of plasmid encoding the hBMP-2 transgene driven by the tested promoters. LacZ electropulsed cells were used as controls $(* p<0.05)$.

short half-life of BMP-2 in vitro (Zhao et al., 2006), these results suggested that a three-week sustained release of BMP-2 can be achieved after gene electrotransfer into rat MSCs. Finally, from day 4 to day 10 after hBMP-2 gene electrotransfer, the GAPDH, $\beta$-actin and EF-1 $\alpha$ promoters led to significantly $(p<0.05)$ greater amounts of secreted BMP- $2 / 24 \mathrm{~h} / 10^{6}$ cells compared to CMV, eIF$4 \mathrm{~A} 1$, fibronectin and $\mathrm{OG} 2$ promoters.

It should be noted that, at day 14, the GAPDH, $\beta$-actin, EF- $1 \alpha$ and OG2 promoters led to significantly $(p<0.05)$ greater secretion of BMP-2 compared to the CMV, eIF-4A1 and fibronectin promoters. These results 


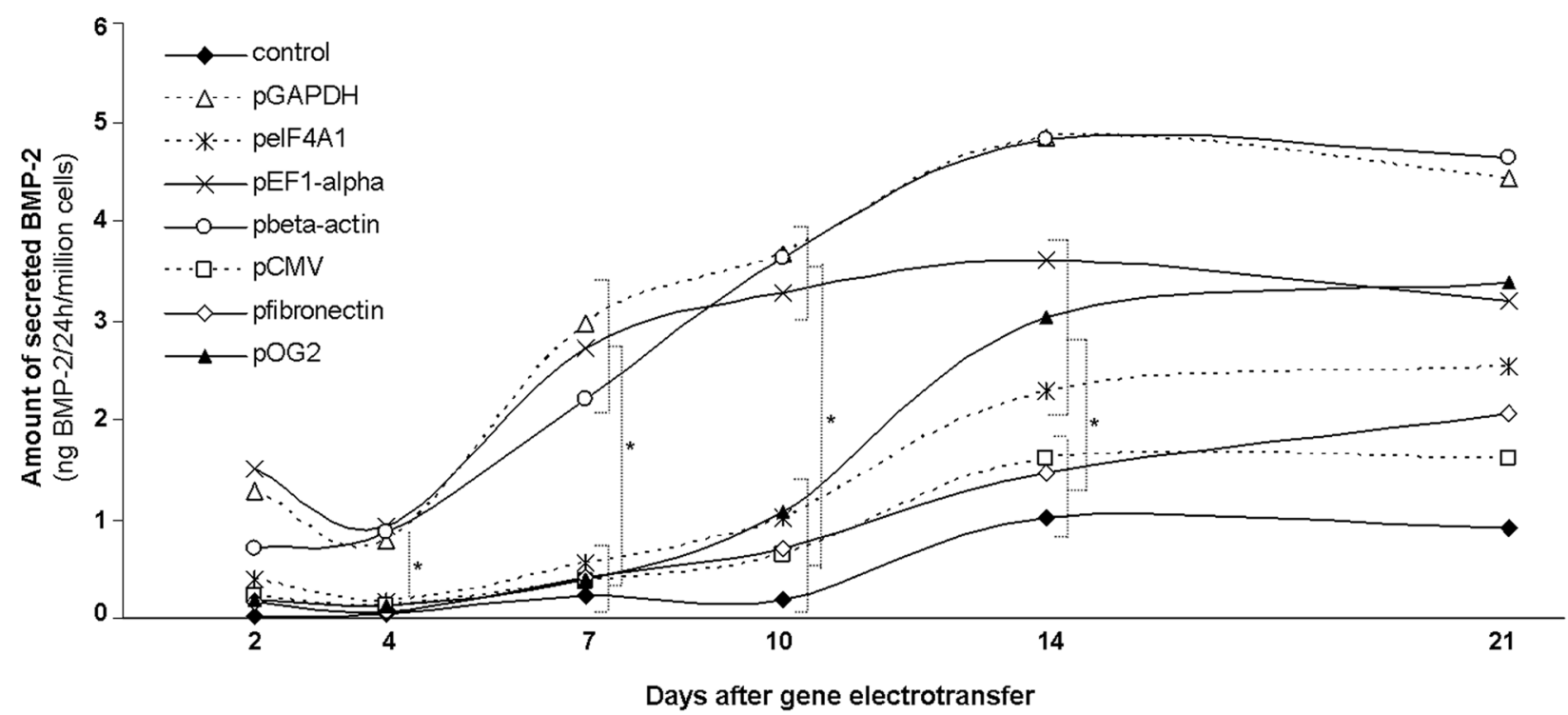

Fig. 2. Kinetics of BMP-2 secretion by MSCs at days 2, 4, 7, 10, 14 and 21 after electrotransfer of an equal number of molecules of plasmid encoding the hBMP-2 transgene under the control of the tested promoters. LacZ electropulsed cells were used as controls. Note: To facilitate reading of the results on this graph, error bars are not included $(* p<0.05)$.

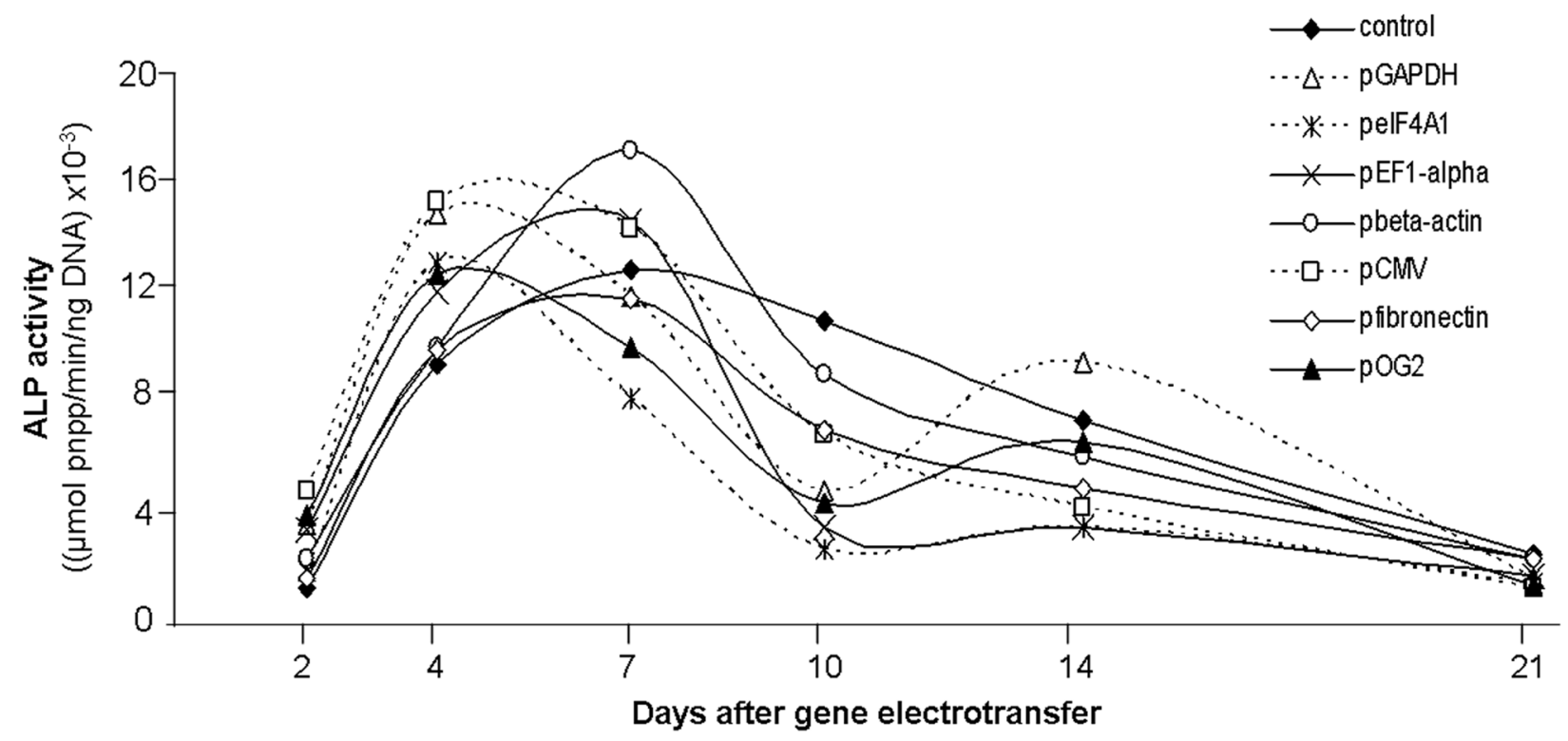

Fig. 3. Kinetics of the ALP activity displayed by MSCs at days 2, 4, 7, 10, 14 and 21 after electrotransfer of an equal number of molecules of plasmid encoding the hBMP-2 transgene under the control of the tested promoters. LacZ electropulsed cells were used as controls.

suggest that the activity of the osteocalcin promoter was enhanced during the time-course of the present study. To address this observation, the osteoblastic differentiation of the electrotransferred MSCs was examined. The kinetics of alkaline phosphatase (ALP) activity (an early marker of osteoblastic differentiation) were investigated. Between day 4 and day 7, MSCs displayed maximal ALP activity, suggesting that cells had initiated osteoblastic differentiation (Fig. 3). In contrast, from day 7 to day 21, ALP activity decreased to basal levels, suggesting that the cells had completed their differentiation to a mature osteoblastic phenotype (Malaval et al., 1994). These results suggest that the osteocalcin promoter may have been activated during the time-course of the study (i.e., during osteoblastic MSC differentiation) and that the activation of the osteocalcin promoter further up-regulated expression of the BMP-2 transgene.

In addition, the lacZ electrotransferred MSCs used as controls displayed increased basal levels of secreted BMP-2 over the time of the study, albeit at statistically lower $(p<0.05)$ levels than the hBMP-2 electrotransferred cells. Under the conditions of these experiments, lacZ electrotransferred cells also displayed similar kinetics of ALP activity compared to hBMP-2-electrotransferred 

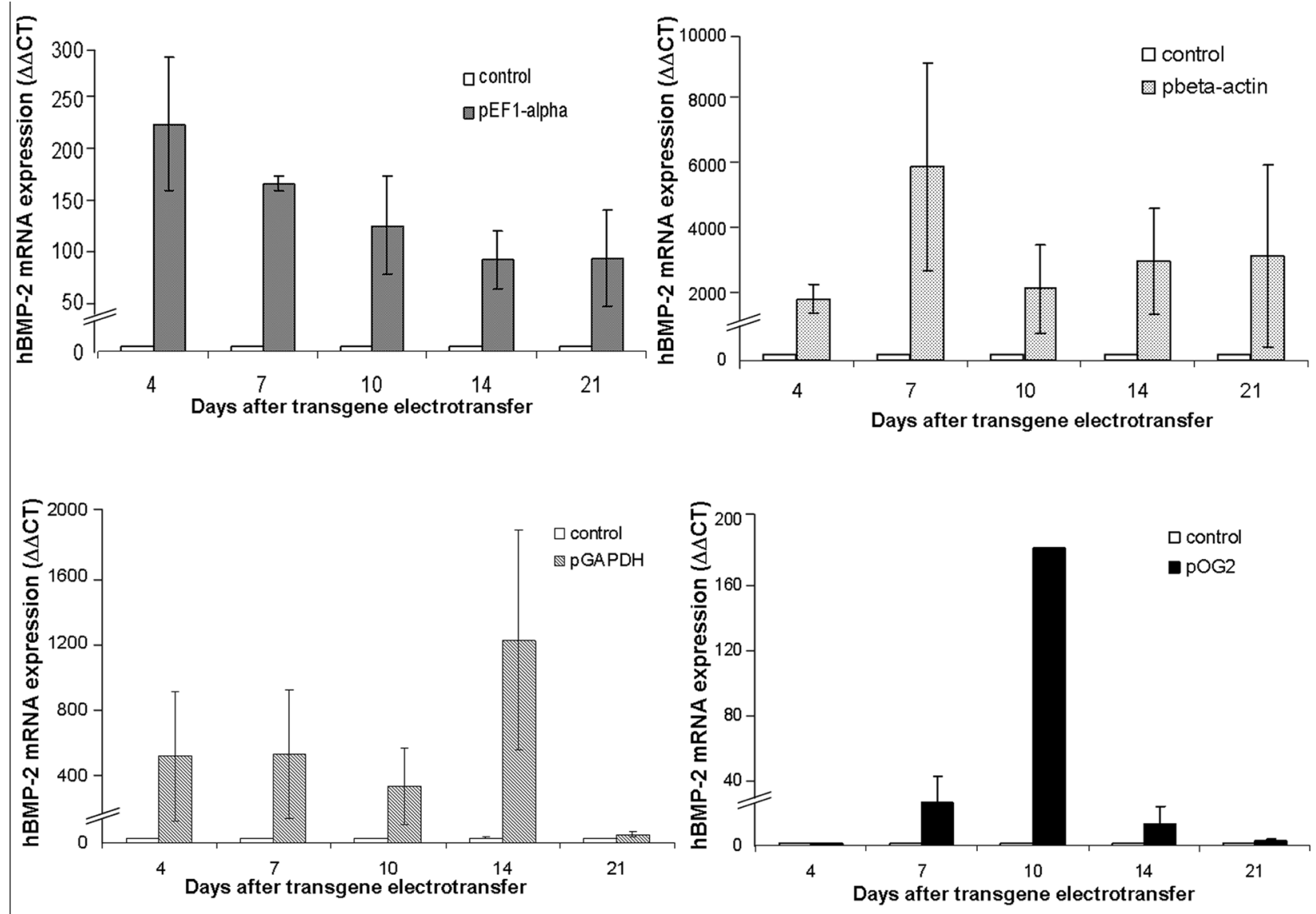

Fig. 4. Kinetics of the hBMP-2 expression by MSCs at days 4, 7, 10, 14 and 21 after electrotransfer of an equal number of molecules of plasmid encoding the hBMP-2 transgene driven by the EF- $1 \alpha$, $\beta$-actin, GAPDH and OG2 promoters. hBMP-2 mRNA levels were normalised first to that of the respective 18S RNA (internal standard), and then to hBMP-2 mRNA levels of lacZ electrotransferred cells (negative control).

MSCs. These results suggested that control rat MSCs might have increased expression of endogenous BMP-2 during osteoblastic differentiation. It should be noted that rat BMP-2 cannot be distinguished from human BMP-2 by the ELISA assay used in the present study. However, using primers specific for hBMP-2, we could distinguish expression of transgene from endogenous (i.e., rat) BMP-2 at the transcript level using RT-PCR.

Effect of the promoter driving the hBMP-2 transgene on its transcriptional activity after transgene transfer into MSCs

The effect of the promoter on the transcriptional activity of the transgene was further investigated at the mRNA level using primers specific for hBMP-2. The EF-1 $\alpha$, GAPDH and $\beta$-actin promoters were selected because they led to the greatest BMP-2 protein secretion rates while the OG-2 promoter was chosen because it modulated BMP-2 protein secretion rates as a function of MSC osteoblastic differentiation. hBMP-2 mRNA expression was measured by semi-quantitative real-time-PCR at days $4,7,10,14$ and 21 after transgene electrotransfer into MSCs. LacZ electrotransferred MSCs were used as controls. hBMP-2 mRNA expression was detected at days 4,7 and 14 after transgene electrotransfer regardless of the promoter driving the transgene (Fig. 4). hBMP-2 mRNA expression driven by the EF- $1 \alpha$, GAPDH or $\beta$-actin promoter was maintained at least until day 21 after transgene electrotransfer. These results provided important evidence that longterm (up to $21 \mathrm{~d}$ ) expression of BMP-2 can be achieved after gene electrotransfer into rat MSCs. In addition, the expressed hBMP-2 mRNA levels depended on the promoter driving the transgene. For example, at $4 \mathrm{~d}$ after transgene electrotransfer, the EF- $1 \alpha$, GAPDH, $\beta$-actin and OG-2 promoters led to approximately a 190-, 500-, 1500- and 2-fold increase of BMP-2 expression over the controls, respectively. Moreover, stable hBMP-2 mRNA expression levels were observed upon electrotransfer of the hBMP-2 transgene driven by either EF- $1 \alpha$, GAPDH or $\beta$-actin promoter over the time course analysis, suggesting that the promoter activity was not affected during the differentiation of the cells. In contrast, electrotransfer of the hBMP-2 transgene driven by the OG-2 promoter led to a respective 2-, 28-, 164-, 21- and 4-fold increase of hBMP-2 expression over the respective controls at days 4, 7, 10, 14 and 21 after transgene electrotransfer. These results support the hypothesis that the osteocalcin promoter was activated during MSC osteoblastic differentiation 


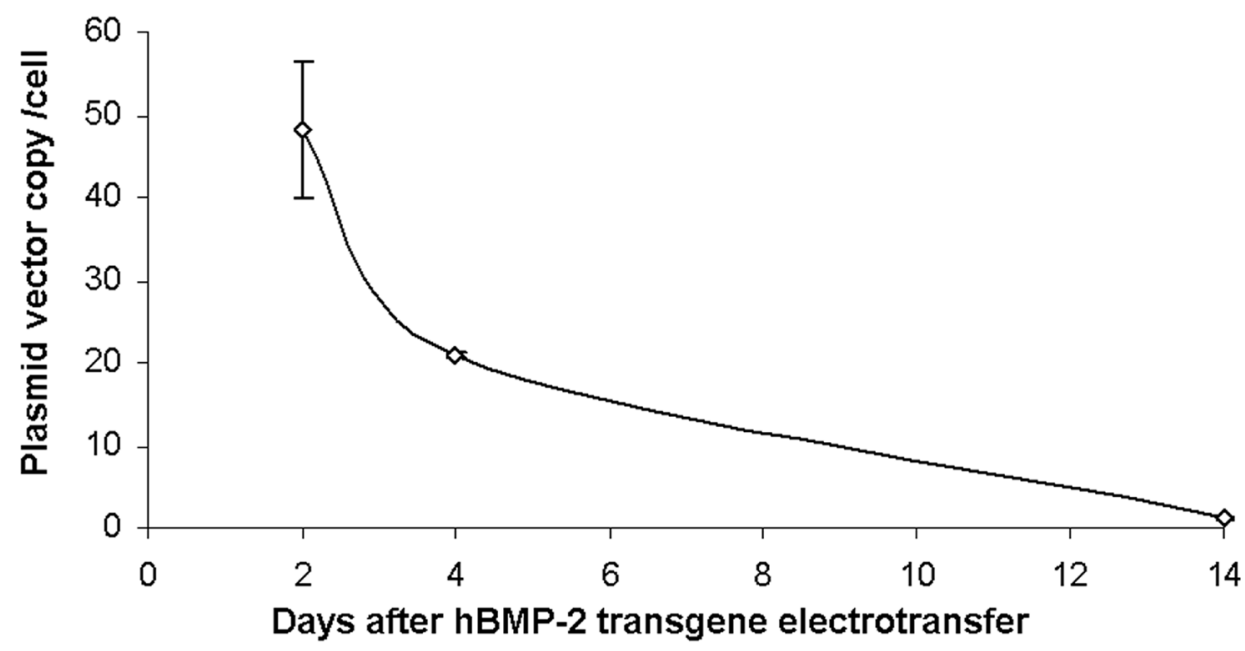

Fig. 5. Kinetics of plasmid copy number at days 2, 4 and 14 after electrotransfer of hBMP-2 plasmid into MSCs.

and that this osteocalcin-promoter activation led to the observed hBMP-2 up-regulation.

\section{Analysis of the plasmid copy number after hBMP-2 plasmid electrotransfer into MSCs \\ Quantitative real-time PCR analysis of the kinetics of hBMP-2 plasmid copy number after electrotransfer into rat MSCs showed $48( \pm 8.00), 21( \pm 0.20)$ and $1( \pm 0.16)$ copies of hBMP-2 plasmid per cell at days 2, 4 and 14 after transgene electrotransfer, respectively (Fig. 5). This decrease in plasmid copy number per cell correlated with cell division and proliferation (data not shown), since gene electrotransfer led to episomal plasmid maintenance.}

\section{Discussion}

Transplantation of MSCs genetically modified with BMP2 transgene is an attractive potential option for the repair of large bone defects because this approach provides essential components for adequate bone repair. In the present study, using rat MSCs overexpressing hBMP-2 after transgene electrotransfer, a method which leads to episomal location of the transferred DNA and limits the risk of DNA integration, we have attempted to optimise BMP-2 transgene expression by investigating the role of the promoter driving the human BMP-2 gene on the level and duration of electrotransferred transgene expression in MSCs.

First, the type of the promoter driving either lacZ or BMP-2 transgene clearly influenced $\beta$-galactosidase and BMP-2 levels expressed by transgene electrotransferred MSCs. The EF- $1 \alpha, \beta$-actin, GAPDH and eIF-4A1 promoters led to significantly $(p<0.05)$ greater $\beta$-galactosidase and BMP-2 production compared to the CMV promoter. This finding is consistent with results that the mammalian EF$1 \alpha$ and ubiquitin $C$ promoters led to transgene expression levels 98- and 20-fold higher, respectively, than those driven by the CMV promoter in mouse MSCs (Byun et al., 2005). In addition, the murine leukaemia virus long terminal repeat promoter led to higher levels of BMP-2 expression in rat MSCs compared to the CMV promoter (Sugiyama et al., 2005). Taken together, these results suggest that the CMV promoter may not be the most effective one in driving maximal BMP-2 expression levels in MSCs.

The promoters of EF- $1 \alpha, \beta$-actin and eIF-4A1 (which are ubiquitously expressed in eukaryotic cells) induced higher levels of transgene expression than viral promoters in haematopoietic and mesenchymal stem cells (Byun et al., 2005; Sakurai et al., 2005), fibroblasts (Sugiyama et al., 1988) and macrophages (Quinn et al., 1999), respectively. Expression of GAPDH, an enzyme involved in glycolysis, can be upregulated by physiological components in certain cell types; for example, by insulin in adipocytes (Ercolani et al., 1988) and by hypoxia in endothelial cells (Graven et al., 1999). Further investigation is needed to elucidate the molecular mechanisms sustaining high levels of transgene expression driven by the eIF-4A1 and GAPDH promoters in MSCs.

Moreover, in the present study, promoter activity depended on the stage of osteoblastic MSC differentiation. Analysis of mRNA levels showed that hBMP-2 expression driven by the EF- $1 \alpha$, GAPDH and $\beta$-actin promoters was stable during the time course (up to $21 \mathrm{~d}$ ) of the present study. In contrast, the levels of hBMP-2 expression driven by the osteocalcin promoter markedly increased over the same time period and correlated to the observed increased BMP-2 production rates; in fact, the production rates driven by the osteocalcin promoter were statistically equivalent to those driven by the strongest promoters (specifically, the EF- $1 \alpha$, GAPDH and $\beta$-actin promoters) at day 14 after transgene electrotransfer into MSCs. Transgene expression driven by the promoter of osteocalcin (a protein specifically expressed by osteoblasts) was evident only from days 7 to 21 after induction of transgenic MSC differentiation into the osteoblastic lineage (Kumar et al., 2005). The data of the present study suggest that, whereas the activity 
of the osteocalcin promoter was predictably weak in undifferentiated MSCs, it might have been boosted during osteoblastic MSC differentiation, resulting in the observed up-regulation in BMP-2 expression.

In contrast, under the conditions in the present study, the fibronectin promoter led to the lowest beta-galactosidase and BMP-2 production rates in undifferentiated rat MSCs after transgene electrotransfer; the activity of the fibronectin promoter was not modulated during MSC osteoblastic differentiation. Fibronectin, a key protein in facilitating wound healing, is generally expressed at low levels in undifferentiated cells. In contrast, its expression is drastically increased after cell differentiation (Choi et al., 1996; Suzuki et al., 1998).

Considering in vivo delivery of BMP-2 by transgenic MSCs for applications in bone repair, the use of a promoter, such as the osteocalcin one, may be inappropriate as it may lead to low levels of BMP-2 expression in undifferentiated cells and to high levels of BMP-2 expression in bonedifferentiated cells. However, considering therapeutic gene delivery for either bone disorders or skeleton tumour metastasis treatment, the osteocalcin promoter may provide an efficacious approach to confine gene expression to bone tissue (Hou et al., 1999). Additional in vivo studies are required to investigate whether the fibronectin promoter could be efficacious in driving high levels of BMP-2 expression for wound healing applications.

One limitation to our model is that the level of BMP-2 expression immediately after transfection (which varies depending on the promoter used) might have influenced MSC proliferation rate and, thereby, downstream levels of BMP-2 expression. However, the electrotransferred MSCs were seeded at a high density and reached confluence within a few days. Such culture conditions might have limited the effects of early BMP-2 expression on cell proliferation and, therefore, the long term levels of BMP-2 expression.

Notably, the present study provided the first evidence that sustained (up to $21 \mathrm{~d}$ ) BMP-2 delivery by MSCs can be achieved after transgene electrotransfer, a reproducible non-viral technique useful for transient expression of therapeutic transgenes (Birkholz et al., 2009; Parham et al., 1998). Kinetics analysis of plasmid copy number showed decreased plasmid copy numbers per cell over the time course of the study; specifically, one copy of plasmid remaining per cell at day 14 after hBMP-2 transgene electrotransfer. Because the kinetics analysis was determined in the total electropulsed cell population which includes hBMP-2 electrotransferred and nonelectrotransferred cells, the results of the present study may not reflect the kinetics of plasmid copy number in the hBMP-2 electrotransferred MSC population. All in all, a strong plasmid dilution correlated with cell division and proliferation was expected to lead to drastic decrease in the hBMP-2 expression levels. In contrast, sustained BMP-2 release for at least 3 weeks was observed in the present study. Independently of the promoter driving the transgene, BMP-2 production rates increased from days 4 to 14 and sustained protein secretion was maintained until at least day 21 after transgene electrotransfer into MSCs. In the past, BMP-2 production by transgenic rat
MSCs was maintained 3 weeks after transgene transfer using recombinant adenoviruses (Feeley et al., 2006). The present study demonstrates the feasibility of gene electrotransfer for efficient BMP-2 transgene delivery into MSCs and for sustained BMP-2 expression, and provides the first in vitro evidence for an alternative to viral methods that permit efficient BMP-2 gene delivery and expression in MSCs but raise safety concerns that are critical when considering clinical applications.

In addition, the present study showed that BMP-2 production correlated with sustained (up to $21 \mathrm{~d}$ ) hBMP-2 mRNA expression. Specifically, a hBMP-2 mRNA increase of 1500-, 1700-, 2380- and 2430-fold over controls was observed at days 4, 10, 14 and 21, respectively, in cells electrotransferred with the hBMP-2 transgene driven by the $\beta$-actin promoter (Fig. 4). In previous studies, mRNA level analysis of hBMP-2 expression in MSCs, transfected with a hBMP-2 plasmid using the electroporation-based technology called "Nucleofector ${ }^{\circledR}$ ", demonstrated that hBMP-2 expression was maximal on day 1 and maintained at significantly elevated levels until day 10, but then decreased to baseline levels (Aslan et al., 2006); this outcome has been a major drawback of most non-viral techniques developed to facilitate the transplantation of in vitro BMP-2 genetically modified MSCs.

Additional in vivo studies are required to investigate whether the levels of BMP-2 expressed by electrotransferred MSCs are physiologically relevant for inducing bone formation. In previous studies, implantation of BMP-2transfected MSCs led to enhanced ectopic bone formation in mouse models (Aslan et al., 2006; Lu et al., 2012; Wegman et al., 2011). Interestingly, the low in vitro levels of BMP-2 expressed by these systems were comparable to the ones observed in our study (e.g., 6-12 ng BMP-2/24 h/ million BMP-2 nucleofected MSCs).

In conclusion, the present study demonstrates that: (i) the EF- $1 \alpha, \beta$-actin and GAPDH promoters are more efficient than the CMV promoter in driving gene expression in rat MSCs; (ii) BMP-2 secretion by genetically modified MSCs was modulated by the promoter driving the transgene, and (iii) sustained (up to $21 \mathrm{~d}$ ) BMP-2 delivery by MSCs was achieved after transgene electrotransfer.

\section{Acknowledgememts}

We thank the Fondation de l'Avenir (Grant ET7-479) for the financial support and express special thanks to R. Bizios and R.M Porter for critical reading of the manuscript. We wish to confirm that there are no known conflicts of interest associated with this publication and there has been no significant financial support for this work that could have influenced its outcome.

\section{References}

Aslan H, Zilberman Y, Arbeli V, Sheyn D, Matan Y, Liebergall M, Li JZ, Helm GA, Gazit D, Gazit Z (2006) Nucleofection-based ex vivo nonviral gene delivery to human stem cells as a platform for tissue regeneration. Tissue Eng 12: 877-889. 
Baltzer AW, Lattermann C, Whalen JD, Wooley P, Weiss K, Grimm M, Ghivizzani SC, Robbins PD, Evans CH (2000) Genetic enhancement of fracture repair: healing of an experimental segmental defect by adenoviral transfer of the BMP-2 gene. Gene Ther 7: 734-739.

Bensidhoum M, Chapel A, Francois S, Demarquay C, Mazurier C, Fouillard L, Bouchet S, Bertho JM, Gourmelon P, Aigueperse J, Charbord P, Gorin NC, Thierry D, Lopez M (2004) Homing of in vitro expanded Stro-1or Stro-1+ human mesenchymal stem cells into the NOD/ SCID mouse and their role in supporting human CD34 cell engraftment. Blood 103: 3313-3319.

Birkholz K, Hombach A, Krug C, Reuter S, Kershaw M, Kampgen E, Schuler G, Abken H, Schaft N, Dorrie J (2009) Transfer of mRNA encoding recombinant immunoreceptors reprograms CD4(+) and CD8(+) T cells for use in the adoptive immunotherapy of cancer. Gene Ther 16: 596-604.

Blum JS, Barry MA, Mikos AG, Jansen JA (2003) In vivo evaluation of gene therapy vectors in ex vivo-derived marrow stromal cells for bone regeneration in a rat criticalsize calvarial defect model. Hum Gene Ther 14: 16891701 .

Byun HM, Suh D, Jeong Y, Wee HS, Kim JM, Kim WK, Ko JJ, Kim JS, Lee YB, Oh YK (2005) Plasmid vectors harboring cellular promoters can induce prolonged gene expression in hematopoietic and mesenchymal progenitor cells. Biochem Biophys Res Commun 332: 518-523.

Choi JY, Lee BH, Song KB, Park RW, Kim IS, Sohn KY, Jo JS, Ryoo HM (1996) Expression patterns of bonerelated proteins during osteoblastic differentiation in MC3T3-E1 cells. J Cell Biochem 61: 609-618.

Chuang CK, Sung LY, Hwang SM, Lo WH, Chen HC, $\mathrm{Hu}$ YC (2007) Baculovirus as a new gene delivery vector for stem cell engineering and bone tissue engineering. Gene Ther 14: 1417-1424.

Daud AI, DeConti RC, Andrews S, Urbas P, Riker AI, Sondak VK, Munster PN, Sullivan DM, Ugen KE, Messina JL, Heller R (2008) Phase I trial of interleukin-12 plasmid electroporation in patients with metastatic melanoma. J Clin Oncol 26: 5896-5903.

Doll RF, Crandall JE, Dyer CA, Aucoin JM, Smith FI (1996) Comparison of promoter strengths on gene delivery into mammalian brain cells using AAV vectors. Gene Ther 3: 437-447.

Duces A, Karaky R, Martel-Renoir D, Mir L, HammaKourbali Y, Bieche I, Opolon P, Delbe J, Courty J, Perricaudet M, Griscelli F (2008) 16-kDa fragment of pleiotrophin acts on endothelial and breast tumor cells and inhibits tumor development. Mol Cancer Ther 7: 2817 2827.

Durieux AC, Bonnefoy R, Freyssenet D (2005) Kinetic of transgene expression after electrotransfer into skeletal muscle: importance of promoter origin/strength. Biochim Biophys Acta 1725: 403-409.

Ercolani L, Florence B, Denaro M, Alexander M (1988) Isolation and complete sequence of a functional human glyceraldehyde-3-phosphate dehydrogenase gene. J Biol Chem 263: 15335-15341.

Feeley BT, Conduah AH, Sugiyama O, Krenek L, Chen IS, Lieberman JR (2006) In vivo molecular imaging of adenoviral versus lentiviral gene therapy in two bone formation models. J Orthop Res 24: 1709-1721.

Ferreira E, Potier E, Logeart-Avramoglou D, Salomskaite-Davalgiene S, Mir LM, Petite H (2008) Optimization of a gene electrotransfer method for mesenchymal stem cell transfection. Gene Ther 15: $537-$ 544.

Friedenstein AJ, Chailakhjan RK, Lalykina KS (1970) The development of fibroblast colonies in monolayer cultures of guinea-pig bone marrow and spleen cells. Cell Tissue Kinet 3: 393-403.

Gill DR, Smyth SE, Goddard CA, Pringle IA, Higgins CF, Colledge WH, Hyde SC (2001) Increased persistence of lung gene expression using plasmids containing the ubiquitin $\mathrm{C}$ or elongation factor 1alpha promoter. Gene Ther 8: 1539-1546.

Graven KK, Yu Q, Pan D, Roncarati JS, Farber HW (1999) Identification of an oxygen responsive enhancer element in the glyceraldehyde-3-phosphate dehydrogenase gene. Biochim Biophys Acta 1447: 208-218.

Hong S, Hwang DY, Yoon S, Isacson O, Ramezani A, Hawley RG, Kim KS (2007) Functional analysis of various promoters in lentiviral vectors at different stages of in vitro differentiation of mouse embryonic stem cells. Mol Ther 15: $1630-1639$.

Hou Z, Nguyen Q, Frenkel B, Nilsson SK, Milne M, van Wijnen AJ, Stein JL, Quesenberry P, Lian JB, Stein GS (1999) Osteoblast-specific gene expression after transplantation of marrow cells: implications for skeletal gene therapy. Proc Natl Acad Sci USA 96: 7294-7299.

Hsu WK, Sugiyama O, Park SH, Conduah A, Feeley BT, Liu NQ, Krenek L, Virk MS, An DS, Chen IS, Lieberman JR (2007) Lentiviral-mediated BMP-2 gene transfer enhances healing of segmental femoral defects in rats. Bone 40: 931-938.

Kumar S, Mahendra G, Ponnazhagan S (2005) Determination of osteoprogenitor-specific promoter activity in mouse mesenchymal stem cells by recombinant adeno-associated virus transduction. Biochim Biophys Acta 1731: 95-103.

Lieberman JR, Le LQ, Wu L, Finerman GA, Berk A, Witte ON, Stevenson S (1998) Regional gene therapy with a BMP-2-producing murine stromal cell line induces heterotopic and orthotopic bone formation in rodents. $\mathrm{J}$ Orthop Res 16: 330-339.

Lou J, Xu F, Merkel K, Manske P (1999) Gene therapy: adenovirus-mediated human bone morphogenetic protein-2 gene transfer induces mesenchymal progenitor cell proliferation and differentiation in vitro and bone formation in vivo. J Orthop Res 17: 43-50.

Lu K, Zeng D, Zhang W, Xia L, Xu L, Jiang X, Zhang F (2012) Ectopic study of calcium phosphate cement seeded with pBMP-2 modified canine bMSCs mediated by a nonviral PEI derivative. Cell Biol Int 36: 119-128.

Malaval L, Modrowski D, Gupta AK, Aubin JE (1994) Cellular expression of bone-related proteins during in vitro osteogenesis in rat bone marrow stromal cell cultures. $\mathrm{J}$ Cell Physiol 158: 555-572.

McMahon JM, Conroy S, Lyons M, Greiser U, O'Shea C, Strappe P, Howard L, Murphy M, Barry F, O'Brien T (2006) Gene transfer into rat mesenchymal stem cells: a 
comparative study of viral and nonviral vectors. Stem Cells Dev 15: 87-96.

Musgrave DS, Bosch P, Lee JY, Pelinkovic D, Ghivizzani SC, Whalen J, Niyibizi C, Huard J (2000) Ex vivo gene therapy to produce bone using different cell types. Clin Orthop Relat Res 378: 290-305.

Neumann E, Schaefer-Ridder M, Wang Y, Hofschneider PH (1982) Gene transfer into mouse lyoma cells by electroporation in high electric fields. EMBO J 1: 841-845.

Olmsted-Davis EA, Gugala Z, Gannon FH, Yotnda P, McAlhany RE, Lindsey RW, Davis AR (2002) Use of a chimeric adenovirus vector enhances BMP2 production and bone formation. Hum Gene Ther 13: 1337-1347.

Parham JH, Iannone MA, Overton LK, Hutchins JT (1998) Optimization of transient gene expression in mammalian cells and potential for scale-up using flow electroporation. Cytotechnology 28: 147-155.

Pittenger MF, Mackay AM, Beck SC, Jaiswal RK, Douglas R, Mosca JD, Moorman MA, Simonetti DW, Craig S, Marshak DR (1999) Multilineage potential of adult human mesenchymal stem cells. Science 284: 143-147.

Pucihar G, Mir LM, Miklavcic D (2002) The effect of pulse repetition frequency on the uptake into electropermeabilized cells in vitro with possible applications in electrochemotherapy. Bioelectrochemistry 57: 167-172.

Quinn CM, Wiles AP, El-Shanawany T, Catchpole I, Alnadaf T, Ford MJ, Gordon S, Greaves DR (1999) The human eukaryotic initiation factor 4AI gene (EIF4A1) contains multiple regulatory elements that direct highlevel reporter gene expression in mammalian cell lines. Genomics 62: 468-476.

Ramezani A, Hawley TS, Hawley RG (2000) Lentiviral vectors for enhanced gene expression in human hematopoietic cells. Mol Ther 2: 458-469.

Sakurai F, Kawabata K, Yamaguchi T, Hayakawa T, Mizuguchi H (2005) Optimization of adenovirus serotype 35 vectors for efficient transduction in human hematopoietic progenitors: comparison of promoter activities. Gene Ther 12: 1424-1433.

Spenger A, Ernst W, Condreay JP, Kost TA, Grabherr R (2004) Influence of promoter choice and trichostatin A treatment on expression of baculovirus delivered genes in mammalian cells. Protein Expr Purif 38: 17-23.

Sugiyama H, Niwa H, Makino K, Kakunaga T (1988) Strong transcriptional promoter in the 5' upstream region of the human beta-actin gene. Gene 65: 135-139.

Sugiyama O, An DS, Kung SP, Feeley BT, Gamradt S, Liu NQ, Chen IS, Lieberman JR (2005) Lentivirusmediated gene transfer induces long-term transgene expression of BMP-2 in vitro and new bone formation in vivo. Mol Ther 11: 390-398.

Suzuki M, Oda E, Nakajima T, Sekiya S, Oda K (1998) Induction of Sp1 in differentiating human embryonal carcinoma cells triggers transcription of the fibronectin gene. Mol Cell Biol 18: 3010-3020.

Tsuchida H, Hashimoto J, Crawford E, Manske P, Lou J (2003) Engineered allogeneic mesenchymal stem cells repair femoral segmental defect in rats. J Orthop Res 21: 44-53.

Urist MR, Mikulski A, Lietze A (1979) Solubilized and insolubilized bone morphogenetic protein. Proc Natl Acad Sci USA 76: 1828-1832.

Wegman F, Bijenhof A, Schuijff L, Oner FC, Dhert WJ, Alblas J (2011) Osteogenic differentiation as a result of BMP-2 plasmid DNA based gene therapy in vitro and in vivo. Eur Cell Mater 21: 230-242.

Wozney JM, Rosen V, Celeste AJ, Mitsock LM, Whitters MJ, Kriz RW, Hewick RM, Wang EA (1988) Novel regulators of bone formation: molecular clones and activities. Science 242: 1528-1534.

Wu MH, Smith SL, Dolan ME (2001) High efficiency electroporation of human umbilical cord blood CD34+ hematopoietic precursor cells. Stem Cells 19: 492-499.

Zhao B, Katagiri T, Toyoda H, Takada T, Yanai T, Fukuda T, Chung UI, Koike T, Takaoka K, Kamijo R (2006) Heparin potentiates the in vivo ectopic bone formation induced by bone morphogenetic protein-2. J Biol Chem 281: 23246-23253.

\section{Discussion with Reviewer}

Reviewer I: The rationale for the experiments is apparently to find the promoter that gives the highest level and longest duration of expression of BMP-2. However, it is unclear whether higher and/or longer levels of expression of BMP2 are needed in vivo. It also is not clear if MSCs are the best cell type in which to express BMP-2 for bone formation. Authors: We agree that, from the literature, it is unclear whether long term delivery of high levels of BMP-2 is required for bone formation in vivo. The best delivery profile may, in fact, depend on the particular clinical case (e.g., fracture versus segmental defect). While it is also unclear whether MSCs are the best cells for BMP-2 delivery in the context of bone formation, we chose to focus on these cells for our promoter comparison study because of their distinct advantages (e.g., extensive expansion capacity; osteogenic potential; engraftment ability). 